\author{
Marquette University \\ e-Publications@Marquette
}

2015

\title{
Factoring Emerging Markets Into the Relationship Between Global Liquidity and Commodities
}

Steven Landgraf

Florida State University

Abdur Chowdhury

Marquette University, abdur.chowdhury@marquette.edu

Follow this and additional works at: https://epublications.marquette.edu/econ_fac

Part of the Economics Commons

\section{Recommended Citation}

Landgraf, Steven and Chowdhury, Abdur, "Factoring Emerging Markets Into the Relationship Between Global Liquidity and Commodities" (2015). Economics Faculty Research and Publications. 579.

https://epublications.marquette.edu/econ_fac/579 


\section{Marquette University}

\section{e-Publications@Marquette}

\section{Dentistry Faculty Research and Publications/School of Dentistry}

This paper is NOT THE PUBLISHED VERSION; but the author's final, peer-reviewed manuscript. The published version may be accessed by following the link in the citation below.

Clinical Oral Investigations, Vol. 19, No. 3 (April 2015): 619-625. DOI. This article is CElsevier and permission has been granted for this version to appear in e-Publications@Marquette. Elsevier does not grant permission for this article to be further copied/distributed or hosted elsewhere without the express permission from Elsevier.

\section{Quality of postoperative pain management after midfacial fracture repair-an outcome- oriented study}

Andre Peisker

Department of Cranio-Maxillofacial \& Plastic Surgery, Jena University Hospital, Jena, Germany

Ulrich Rieger

Interdisciplinary Research Group of Computational Medicine, Jena University Hospital, Jena, Germany Department of Plastic and Aesthetic Surgery, Reconstructive and Hand Surgery, St. Markus Hospital, Johann Wolfgang von Goethe University, Frankfurt, Germany

Gabriel Djedovic Interdisciplinary Research Group of Computational Medicine, Jena University Hospital, Jena, Germany Department of Plastic and Aesthetic Surgery, Reconstructive and Hand Surgery, St. Markus Hospital, Johann Wolfgang von Goethe University, Frankfurt, Germany

Arndt Guentsch

Interdisciplinary Research Group of Computational Medicine, Jena University Hospital, Jena, Germany Department of Plastic and Aesthetic Surgery, Reconstructive and Hand Surgery, St. Markus Hospital, Johann Wolfgang von Goethe University, Frankfurt, Germany 


\section{Oliver Schaefer}

Interdisciplinary Research Group of Computational Medicine, Jena University Hospital, Jena, Germany Department of Plastic and Aesthetic Surgery, Reconstructive and Hand Surgery, St. Markus Hospital, Johann Wolfgang von Goethe University, Frankfurt, Germany

\section{Eric Venth}

Department of Cranio-Maxillofacial \& Plastic Surgery, Jena University Hospital, Jena, Germany

\section{Marta Gomez Dammeier}

Department of Cranio-Maxillofacial \& Plastic Surgery, Jena University Hospital, Jena, Germany Interdisciplinary Research Group of Computational Medicine, Jena University Hospital, Jena, Germany

\section{Winfried Meissner}

Department of Anesthesiology and Intensive Care Medicine, Jena University Hospital, Jena, Germany

\section{Abstract}

\section{Objectives}

There is a lack of literature regarding the procedure-specific quality of acute postoperative pain management after midfacial fracture repair. The purpose of the presented prospective clinical study was to evaluate postoperative pain management after surgical repair of midfacial fractures.

\section{Materials and methods}

Eighty-five adults were evaluated on the first postoperative day following midfacial repair using the questionnaire of the Quality Improvement in Postoperative Pain Management (QUIPS) project. The main outcome measures were patients' characteristics and clinical- and patient-reported outcome parameters.

\section{Results}

Overall, pain on the first postoperative day was moderate. A significant correlation between process and outcome parameters could be shown. Duration of surgery above the calculated median was significantly associated with higher maximum pain intensity $(p=0.017)$. Patients requiring opioids in the recovery room presented significantly higher pain on activity $(p=0.029)$ and maximum pain $(p=0.035)$. Sleeping impairment $(p=0.001)$ and mood disturbance $(p=0.008)$ were significantly more prevalent in patients undergoing repair of a centrolateral midfacial fracture.

\section{Conclusions}

QUIPS is a simple and qualified tool to evaluate the procedure specific quality of acute postoperative pain management. Pain on the first postoperative day following midfacial fracture repair seems overall to be moderate. Nearly a third of the patients showed inadequate postoperative pain management. To prevent inadequate postoperative pain management, it is necessary to establish a continued procedure-specific outcome measurement.

\section{Keywords}

Postoperative pain Quality management QUIPS Zygomaticomaxillary complex fracture Blow-out fracture Orbital floor fracture 


\section{Clinical relevance}

Repair of a centrolateral midfacial fracture, long duration of surgery, and need of opioids in the recovery room seem to be associated with higher postoperative pain levels.

\section{Introduction}

Management of postoperative pain is part of the daily clinical routine of every maxillofacial surgeon. An adequate postoperative pain management is essential in the postoperative care and is an ethical obligation [1]. Poorly managed postoperative pain may lead to increased suffering, increased costs of care, and chronic pain [ $\underline{2}$, 3].

However, there seems to be a worldwide undersupply of adequate postoperative pain medications $[\underline{4}, \underline{5}, \underline{6}]$. Investigations from various countries confirm that the quality of acute pain management is unsatisfying $[\underline{5}, \underline{7}, \underline{8}$, $\underline{9}, \underline{10}$.

Over the last decade, several clinical guidelines were published, which helped to improve processes and structures of pain management, however, outcomes such as pain intensity did not [11, $\underline{12}]$.

The efficiency of analgesic interventions varies widely between different procedures. Therefore, for optimal pain management, surgery-specific approaches should be considered [2] .

Surgical repair of centrolateral and lateral midfacial fractures as well as isolated fractures of the orbital floor is a frequently and routinely performed procedure in every maxillofacial surgery department. Although it is of the biggest clinical interest to investigate postoperative pain, there is a lack of knowledge in the literature regarding procedure-specific and quality of pain management after midfacial fracture repair.

The presented prospective clinical study investigates postoperative quality of pain management on the first postoperative day after midfacial fracture repair. A standardized assessment of patients' characteristics, process, and outcome parameters of postoperative pain management was performed using the questionnaire of the Quality Improvement in Postoperative Pain Management (QUIPS) system.

\section{Patients and method}

The presented prospective study was performed at the Department of Maxillofacial Surgery/Plastic Surgery of the University Hospital Jena. Institutional review board approval (ethics committee of the University Hospital Jena at the Medical Faculty) was obtained before the study was initiated.

Patients who underwent surgical repair of a lateral or centrolateral midfacial fracture or an isolated orbital floor fracture were included. Surgical approaches as well as reposition and osteosynthetic stabilization of fractures were performed in a standardized manner. The lateral and centrolateral midface were operated via a gingival approach, the lateral orbital rim via an upper eyelid and the orbital floor via a transconjunctival approach [13] . Local anesthesia in terms of $2 \%$ lignocaine with 1:100,000 epinephrine (mibe GmbH, Brehna, Germany) was only injected in the area of the gingival approach. If necessary, alloplastic reconstruction of the orbital floor was performed by using a polydioxanone sheet (PDS, Ethicon Products, Norderstedt, Germany), in severe cases by a titanium mesh (Synthes, Umirch, Germany). Osteosynthetic stabilization was performed using mini-plates (sutura frontozygomatica, medial and lateral buttress) and micro-plates (inferior orbital rim) (Medartis, Basel, Switzerland).

Patients received a postoperative nausea and vomiting prophylaxis according to their individual risk profile, using granisetron and dexamethasone. Anesthesia and pain treatment was performed according to hospital 
standards (premedication: midazolam; intraoperative analgesics: sufentanil and metamizole (dipyrone); postoperative analgesics: metamizole as routine treatment combined with piritramide on an as-needed basis; local cool packs). However, deviation from these standards was allowed to physicians' discretion in case of allergies, patients' preferences, and other reasons.

Demographic and procedure-specific characteristics of each patient were recorded using a standardized and categorized database including, e.g., age, gender, body mass index (BMI), ASA status, and duration of surgery. The assessment of postoperative pain was performed at the first postoperative day not exceeding $24 \mathrm{~h}$ after surgery by a study nurse not being involved in the routine care of the patients. After a standardized instruction, the first part of the QUIPS questionnaire, which covers outcome parameters of postoperative pain management, was given to the patient. It was answered and completed by the patient him- or herself. Eleven-point numeric rating scales were used to evaluate the intensity of the parameter. In general, higher numbers indicate more pain $(0=$ no pain, $10=$ maximal pain). Dichotomous questions were answered with yes or no.

The second part of the questionnaire covered the relevant process parameters of postoperative pain management and was filled out by a study nurse. Data were collected without systematization of analgesic medication to record the postoperative pain treatment as it was done daily. All data were anonymized and transferred to the external database of QUIPS via Internet (http://www.quips-projekt.de).

Postoperative pain medication was reduced and finally stopped when adequate analgesia and pain reduction was achieved.

\section{Statistical analysis}

If not indicated otherwise, data are presented as mean and standard deviation. Outcome and process parameters are given descriptively (Tables $\underline{1}$ and $\underline{2}$ ). The continuous variables age and duration of surgery were transformed into dichotomous variables using the median values as separator. Non-parametric Mann-Whitney $U$ tests were applied to compare continuous variables between resulting independent subgroup pairs, KruskalWallis test was performed to compare results between multiple subgroups. Pearson's Chi-square tests were applied to compare categorized data of independent subgroups (see Tables $\underline{3}$ and $\underline{4}$ ). In cases where requirements for Pearson's Chi-square test were not met, Fisher's Exact Test was applied. In cases where multiple groups were compared, nominal $p$ values of two-tailed tests are reported. A value of $p<0.05$ was taken to be significant. All calculations were conducted with SPSS Version 21.0 for Windows (SPSS, Inc, Chicago, IL).

Table 1. QUIPS outcome parameters after midfacial fracture repair ( $n=85$ patients)

\begin{tabular}{|l|l|}
\hline Pain on activity & $2.76 \pm 1.986$ \\
\hline Maximum pain intensity & $3.78 \pm 2.701$ \\
\hline Maximum pain intensity & $1.29 \pm 1.379$ \\
\hline Satisfaction with pain intensity & $12.25 \pm 2.400$ \\
\hline $\begin{array}{l}\text { Preoperative pain management counseling } \\
\text { Yes, only general }\end{array}$ & 60 \\
\hline $\begin{array}{l}\text { Yes, also specific } \\
\text { No }\end{array}$ & 19 \\
\hline $\begin{array}{l}\text { Chronic pain before surgery } \\
\text { Yes }\end{array}$ & 6 \\
\hline No & 72 \\
\hline Mobility impairment because of pain & 13 \\
\hline Yes & 61 \\
\hline No & 24 \\
\hline Breathing impairment because of pain & \\
\hline
\end{tabular}




\begin{tabular}{|l|l|}
\hline Yes & 69 \\
\hline No & 16 \\
\hline \begin{tabular}{|l|} 
Sleeping impairment because of pain \\
Yes
\end{tabular} & 67 \\
\hline No & 18 \\
\hline $\begin{array}{l}\text { Mood impairment because of pain } \\
\text { Yes }\end{array}$ & 61 \\
\hline No & 24 \\
\hline $\begin{array}{l}\text { Desire for pain medication } \\
\text { Yes }\end{array}$ \\
\hline No & 79 \\
\hline Drowsiness since surgery & 6 \\
\hline Yes & \\
\hline No & 41 \\
\hline
\end{tabular}

Table 2. QUIPS process parameter after midfacial fracture repair ( $n=85$ patients) Sedative as premedication

\begin{tabular}{|l|l|}
\hline Midazolam & 81 \\
\hline Non opioid intraoperative & 4 \\
\hline Metamizole & 79 \\
\hline Parecoxib & 1 \\
\hline No & 6 \\
\hline Opioid intraoperative & \\
\hline Sufentanil & 84 \\
\hline Remifentanil & 5 \\
\hline Piritramide & 5 \\
\hline No & 1 \\
\hline Prednisolone & \\
\hline Yes & 79 \\
\hline No & 6 \\
\hline PONV prophylaxis & 59 \\
\hline Granisetron & 44 \\
\hline Dexamethasone & 25 \\
\hline MCP & 0 \\
\hline Dimenhydrinal & 0 \\
\hline No & 26 \\
\hline Clonidine perioperatively & \\
\hline Yes & 3 \\
\hline No & 82 \\
\hline Non-opioid on ward & \\
\hline Metamizole & 78 \\
\hline Paracetamol & 1 \\
\hline Ibuprofen & 5 \\
\hline No & 5 \\
\hline Opioid on ward & 0 \\
\hline
\end{tabular}


Table 3. Relation between process and outcome parameters concerning postoperative pain after midfacial fracture repair (Part 1)

\begin{tabular}{|c|c|c|c|c|c|c|}
\hline & $\begin{array}{l}\text { Pain on } \\
\text { activity } \\
(0-10)\end{array}$ & $\begin{array}{l}\text { Maximum } \\
\text { pain } \\
\text { intensity } \\
(0-10)\end{array}$ & $\begin{array}{l}\text { Minimum } \\
\text { pain } \\
\text { intensity } \\
(0-10)\end{array}$ & $\begin{array}{l}\text { Satisfaction } \\
\text { with pain } \\
\text { intensity (0- } \\
\text { 15) }\end{array}$ & $\begin{array}{l}\text { Mobility } \\
\text { decreased } \\
\text { (n) }\end{array}$ & $\begin{array}{l}\text { Breathing } \\
\text { disturbance } \\
\text { (n) }\end{array}$ \\
\hline $\begin{array}{l}\text { Age } \\
\text { (median = } 59 \text { years) }\end{array}$ & 0.101 & 0.237 & 0.653 & 0.587 & 1.000 & 0.785 \\
\hline Gender & 0.669 & 0.279 & 0.681 & 0.071 & 1.000 & 0.259 \\
\hline BMI ( $\leq 25$ vs. $>25)$ & 0.723 & 0.422 & 0.642 & 0.058 & 0.399 & 0.272 \\
\hline ASA (I vs. II-III) & 0.094 & 0.147 & 0.161 & 0.767 & 0.802 & 0.766 \\
\hline $\begin{array}{l}\text { Duration of surgery } \\
\text { (median } \\
\text { time }=65 \mathrm{~min} \text { ) }\end{array}$ & 0.081 & 0.017 & 0.196 & 0.488 & 0.056 & 0.102 \\
\hline$<$ Median $(n=43)$ & & $3.1 \pm 2.6$ & & & & \\
\hline$>$ Median $(n=42)$ & & $4.5 \pm 2.6$ & & & & \\
\hline $\begin{array}{l}\text { Counseling (specific } \\
\text { vs. general vs. no) }\end{array}$ & 0.323 & 0.664 & 0.796 & 0.394 & 0.567 & 1.000 \\
\hline $\begin{array}{l}\text { Premedication } \\
\text { midazolam }\end{array}$ & 0.543 & 0.457 & 0.461 & 0.368 & 0.554 & 1.000 \\
\hline $\begin{array}{l}\text { Sufentanil } \\
\text { intraoperative }\end{array}$ & 1.000 & 0.882 & 0.859 & 0.706 & 1.000 & 1.000 \\
\hline $\begin{array}{l}\text { Clonidine } \\
\text { perioperative }\end{array}$ & 0.674 & 0.993 & 0.643 & 0.658 & 0.555 & 0.470 \\
\hline PONV prophylaxis & 0.698 & 0.642 & 0.689 & 0.191 & 1.000 & 0.369 \\
\hline Granisetron & 0.329 & 0.159 & 0.098 & 0.956 & 0.479 & 0.169 \\
\hline Dexamethasone & 0.317 & 0.430 & 0.028 & 0.080 & 0.122 & 1.000 \\
\hline Yes $(n=60)$ & & & $1.5 \pm 1.4$ & & & \\
\hline No $(n=25)$ & & & $0.8 \pm 1.2$ & & & \\
\hline Prednisolone & 0.467 & 0.361 & 0.310 & 0.238 & 1.000 & 1.000 \\
\hline $\begin{array}{l}\text { Non-opioid } \\
\text { intraoperative }\end{array}$ & 0.938 & 0.742 & 0.310 & 0.893 & 0.671 & 0.589 \\
\hline Opioid intraoperative & 1.000 & 0.882 & 0.859 & 0.706 & 1.000 & 1.000 \\
\hline $\begin{array}{l}\text { Opioid in recovery } \\
\text { room }\end{array}$ & 0.029 & 0.035 & 0.078 & 0.497 & 0.213 & 0.775 \\
\hline Yes $(n=53)$ & $2.4 \pm 1.7$ & $3.3 \pm 2.6$ & & & & \\
\hline No $(n=32)$ & $3.4 \pm 2.2$ & $4.6 \pm 2.8$ & & & & \\
\hline Non-opioid on ward & 0.419 & 0.471 & 0.292 & 0.204 & 1.000 & 1.000 \\
\hline Opioid on ward & 0.181 & 0.224 & 0.381 & 0.190 & 0.540 & 0.726 \\
\hline
\end{tabular}

Table 4. Relation between process and outcome parameters concerning postoperative pain after midfacial fracture repair (Part 2)

\begin{tabular}{|l|l|l|l|l|l|l|l|}
\hline & $\begin{array}{l}\text { Sleeping } \\
\text { impairmen } \\
\mathbf{t}(\mathbf{n})\end{array}$ & $\begin{array}{l}\text { Mood } \\
\text { disturbanc } \\
\mathbf{e}(\mathbf{n})\end{array}$ & $\begin{array}{l}\text { Desire for } \\
\text { pain } \\
\text { medicatio } \\
\mathbf{n}(\mathbf{n})\end{array}$ & $\begin{array}{l}\text { Drowsines } \\
\mathbf{s}(\mathbf{n})\end{array}$ & $\begin{array}{l}\text { Nause } \\
\mathbf{a}(\mathbf{n})\end{array}$ & $\begin{array}{l}\text { Vomitin } \\
\mathbf{g}(\mathbf{n})\end{array}$ & $\begin{array}{l}\text { Chronic } \\
\text { pain } \\
\text { preoperativ } \\
\mathbf{e}(\mathbf{n})\end{array}$ \\
\hline $\begin{array}{l}\text { Age } \\
\text { (median =59 year } \\
\text { s) }\end{array}$ & 0.433 & 0.238 & 0.204 & 1.000 & 1.000 & 1.000 & 0.232 \\
\hline
\end{tabular}




\begin{tabular}{|c|c|c|c|c|c|c|c|}
\hline Gender & 0.591 & 0.464 & 0.393 & 1.000 & 0.712 & 1.000 & 1.000 \\
\hline BMI ( $\leq 25$ vs. $>25$ ) & 1.000 & 0.804 & 0.402 & 0.826 & 0.468 & 0.139 & 0.354 \\
\hline ASA (I vs. II-III) & 0.022 & 0.119 & 0.377 & 0.102 & 1.000 & 1.000 & 0.211 \\
\hline ASA I $(n=27)$ & $n=10$ & & & & & & \\
\hline $\begin{array}{l}\text { ASA II-III } \\
(n=58)\end{array}$ & $n=8$ & & & & & & \\
\hline $\begin{array}{l}\text { Duration of } \\
\text { surgery (median } \\
\text { time }=65 \mathrm{~min} \text { ) }\end{array}$ & 0.117 & 0.056 & 0.676 & 1.000 & 1.000 & 0.241 & 0.228 \\
\hline $\begin{array}{l}\text { Counseling } \\
\text { (specific vs. } \\
\text { general vs. no) }\end{array}$ & 0.554 & 0.775 & 0.612 & 1.000 & 1.000 & 1.000 & 0.723 \\
\hline $\begin{array}{l}\text { Premedication } \\
\text { midazolam }\end{array}$ & 0.520 & 1.000 & 1.000 & 0.603 & 1.000 & 1.000 & 1.000 \\
\hline $\begin{array}{l}\text { Sufentanil } \\
\text { intraoperative }\end{array}$ & 0.212 & 0.282 & 1.000 & 0.482 & 1.000 & 1.000 & 1.000 \\
\hline $\begin{array}{l}\text { Clonidine } \\
\text { perioperative }\end{array}$ & 1.000 & 0.555 & 1.000 & 0.607 & 1.000 & 1.000 & 1.000 \\
\hline PONV prophylaxis & 0.413 & 0.604 & 0.171 & 0.818 & 1.000 & 1.000 & 1.000 \\
\hline Granisetron & 0.190 & 0.479 & 0.204 & 0.829 & 0.147 & 0.230 & 1.000 \\
\hline Dexamethasone & 0.567 & 1.000 & 1.000 & 1.000 & 0.007 & 0.084 & 1.000 \\
\hline Yes $(n=60)$ & & & & & $n=2$ & & \\
\hline No $(n=25)$ & & & & & $n=6$ & & \\
\hline Prednisolone & 0.106 & 0.671 & 1.000 & 0.423 & 0.639 & 1.000 & 0.584 \\
\hline $\begin{array}{l}\text { Non-opioid } \\
\text { intraoperative }\end{array}$ & 0.334 & 1.000 & 0.364 & 1.000 & 0.096 & 1.000 & 1.000 \\
\hline $\begin{array}{l}\text { Opioid } \\
\text { intraoperative }\end{array}$ & 0.212 & 0.282 & 1.000 & 0.482 & 1.000 & 1.000 & 1.000 \\
\hline $\begin{array}{l}\text { Opioid in recovery } \\
\text { room }\end{array}$ & 0.587 & 0.631 & 0.668 & 0.072 & 0.468 & 1.000 & 0.223 \\
\hline $\begin{array}{l}\text { Non-opioid on } \\
\text { ward }\end{array}$ & 0.579 & 0.315 & 1.000 & 0.361 & 0.398 & 1.000 & 0.573 \\
\hline Opioid in the ward & 0.293 & 0.344 & 0.065 & 1.000 & 0.626 & 1.000 & 0.448 \\
\hline
\end{tabular}

\section{Results}

A total of 85 patients were enrolled during the study period of 6 months (April to September 2013). Fifty $(58.8 \%)$ patients were males and 35 (41.2\%) females. Mean age was $56.2 \pm 20.7$ years at time of evaluation. Mean body height and mean body weight was $172.3 \pm 9.3 \mathrm{~cm}$ and $73.3 \pm 14.6 \mathrm{~kg}$, respectively. Thirteen patients (15.3\%) regularly used pain medicaments for pre-existing chronic pain related to other diseases. Twenty-seven (31.8\%) patients were classified under ASA 1, 43 (50.6\%) ASA 2, and 15 (17.6\%) ASA 3.

Forty-four (51.8\%) patients showed a lateral midfacial fracture, 21 (24.7\%) a centrolateral midfacial fracture and $20(23.5 \%)$ an isolated orbital floor fracture. Mean duration of surgery was $82.9 \pm 57.4 \mathrm{~min}$.

Results of the QUIPS questionnaire regarding the patient-reported outcome parameters are given in Table 1 . Minimal pain was on average $1.29 \pm 1.38$ on the 11-step Numeric Rating Scale (NRS). Strain-related pain increased to $2.76 \pm 1$.99. Maximum pain levels showed a mean of $3.78 \pm 2.70$. Overall, satisfaction with pain therapy was very high. Only 19 (22.4\%) of the patients reported to have received preoperative pain counseling. 
Concerning pain-related complaints, nearly a quarter of the patients reported pain-related impairment of mobility and disturbance of mood. Nearly every fifth patient reported impairment of breathing and sleeping. Only six (7.1 \%) patients desired more pain medication. Eight $(9.4 \%)$ patients reported postoperative nausea and two $(2.4 \%)$ vomiting.

Details of the pain management performed are given in Table $\underline{2}$. The standard sedative for premedication was midazolam. Intraoperatively, nearly all patients received sufentanil and metamizol. Clonidine was rarely applied. When a gingival approach was performed, patients received local anesthesia using $2 \%$ lignocaine with 1:100,000 epinephrine (mibe GmbH, Germany). Prophylaxis of postoperative nausea and vomiting (PONV) was performed in nearly half of the patients by granisetron and in a quarter of the patients by dexamethasone.

In the recovery room, 32 (37.6\%) patients received opioids, of which 31 (96.9\%) received piritramide. The other patients did not require additional pain medication.

In the ward, $91.8 \%$ of the patients received metamizol applied in a dosage of $4 \times 1 \mathrm{~g}$. None of the patients were given additional opioids in the ward. All patients received cold packs as physical pain therapy. Written individual instructions for pain therapy and routine pain documentation were recorded in all patients.

Relations between the above-described outcome and process parameters are given in Tables $\underline{3}$ and $\underline{4}$. Patients exhibiting an American Society of Anesthesiologists (ASA) status of 1 reported significantly more often sleeping impairment $(p=0.022)$. Duration of surgery above the calculated median of 65 min was related with significantly higher postoperative maximal pain $(p=0.017)$. Patients receiving dexamethasone showed significantly less minimal pain $(p=0.028)$ but presented more often postoperative nausea $(p=0.007)$. Those 32 patients that received opioids in the recovery room presented significantly higher levels of strain-related pain $(p=0.029)$ and higher maximal pain levels $(p=0.035)$.

The type of midfacial fracture showed a significant interference with the categorized data of sleeping $(p=0.001)$ and $\operatorname{mood}(p=0.008)$ in a multivariate analysis. The type of fracture did not significantly influence pain intensity. Pearson's Chi-square was used to analyse associations within the subgroups. After repair of a centrolateral midfacial fracture, significantly more patients exhibited sleeping impairment compared to lateral midfacial fractures $(p=0.001)$ and orbital floor fractures $(p=0.006)$. Also, impairment of mood was significantly more often reported when a centrolateral midfacial fracture was repaired compared to lateral midfacial fractures $(p=0.048)$ and orbital floor fractures $(p=0.006)$. There was no significant difference between lateral midfacial fractures and orbital floor fractures.

\section{Discussion}

Inadequate postoperative pain results in patient discomfort and may decrease patient satisfaction [14]. It may even increase the risk for pulmonary and cardiovascular complications and also contribute to the risk of development of chronic pain. Thus, adequate pain management is an essential part of postoperative care [15, $\underline{16}, \underline{17}]$.

Intraoperatively as well as in the recovery room, pain management is controlled by anesthesiologists, whereas surgeons are responsible for the postoperative recovery and pain management in the ward.

Currently, it is an almost ubiquitous phenomenon that postoperative pain management especially in the ward is insufficient. The main reasons for insufficient pain management are not attributed to medical problems; numerous studies regarding the appropriate technique in analgesic treatment are available. There are indications that insufficient postoperative pain management is associated with inadequate exploitation of existing knowledge among health care professionals and patients, lack of institutional commitment, regulatory concerns, and limited access to and reimbursement for interdisciplinary care $\underline{2}, \underline{18}, \underline{19}$ ]. 
Currently, surgeons regularly seek advice on principles for postoperative pain management in general guidelines for acute pain management or in major textbooks [2]. The recommendations of these guidelines and books are predominately based on studies in poorly defined surgical procedures [2]. The same applies to the published postoperative pain management guideline for the head and neck area [20].

This is of special interest to the maxillofacial surgeon as there are hints for a large variation in the intensity and character of pain after different types of head and neck surgery. E.g., it has been shown that patients undergoing surgery of the oral region, pharynx, larynx, neck, and salivary glands had a 4 to 10 times higher risk of intense postoperative pain compared to patients undergoing ear surgery [15]. Thus, it is of special interest for maxillofacial surgeons to perform further investigations to optimize the outcome of acute postoperative pain management.

In the presented study, we evaluated the quality of acute postoperative pain management after midfacial fracture repair, which is one of the most frequently performed standardized procedures in nearly all maxillofacial departments, using QUIPS.

In other disciplines of surgery, QUIPS has already been shown helpful to significantly improve postoperative pain management quality $[\underline{21}, \underline{24}]$.

Despite the presented qualities of QUIPS like standardized data acquisition with validated questionnaires and independent and trained staff performing the interviews, some limitations have to be mentioned: a limitation of our study is that the application of QUIPS does not allow conclusions about the further course of postoperative pain after the first postoperative day. Because normally pain decreases after the first postoperative day, it might be assumed that the postoperative pain therapy reported here is effective over the first postoperative day [15] . Another limitation is the absence of preoperative pain assessment. Thus, we could not differentiate between disease-caused and surgically induced pain. Furthermore, the presented data have a monocentric character. Thus, it is not possible to deduce from our data on a general situation. Also, a Hawthorne effect, describing unexpected and unexplained reactivity to experimentation in human subjects who are aware of their participation in a study, cannot be excluded. Usually, a Hawthorne effect improves rather than deteriorates study outcomes.

Regarding the presented results of our study, minimal and maximal as well as pain on activity on the first postoperative day may be considered as moderate. On the 11-step NRS, pain ranged from 1.5 to 4.2 . This rating is supported by the high level of patients' satisfaction with the postoperative analgesic treatment and the low number of patients reporting wish for more pain medication. In comparison to earlier reported maximum pain levels in osteosynthetic repair of a forearm fracture (5.8), patients showed less pain [21].

Regarding the investigated relations between process and outcome parameters, the duration of surgery presented a significant influence on postoperative maximum pain intensity. Patients exhibiting a duration of surgery above the median of 65 min showed significantly higher pain levels in contrast to patients with shorter surgeries $(p=0.017)$. Higher duration of surgery may be interpreted as a hint on a complicated, very dislocated fracture requiring extensive preparation, exposure, and manipulation leading to a bigger surgical-induced trauma and higher levels of postoperative maximum pain.

An association between extent of surgical trauma and patient-reported outcomes is further supported by the observation of significantly higher rate of sleeping impairment and mood disturbance in centrolateral midfacial fractures compared to lateral midfacial fractures and orbital floor fractures. Repair of centrolateral midfacial fractures mostly requires more surgical manipulation, e.g., an extended reduction and additional osteosynthesis of the medial buttress, possibly resulting in the reported differences in pain-related impairment. Despite these 
facts and the given observations, we did not detect significantly higher pain levels in patients presenting with centrolateral fractures.

Application of dexamethasone to prevent PONV led to significantly lower levels of minimum pain $(p=0.028)$. This observation may be related to the antiphlogistic potency of dexamethasone. The higher rate of postoperative nausea in patients receiving dexamethasone may be related to higher anamnestic risk of PONV and consecutive medication with dexamethasone. In general, the application of corticosteroids to reduce postoperative swelling is part of a controversial discussion in the literature.

Of special interest were the observed significantly higher levels of postoperative pain on activity $(p=0.029)$ and maximum pain $(p=0.035)$ in patients receiving opioids in the recovery room. Higher pain intensity in patients receiving opioids in the recovery room compared to those without opioid medication might be explained by the fact that opioid treatment was done on an as-needed base, i.e., those patients with higher pain intensity requested (and received) more opioids than those with less pain in the recovery room.

On first sight, this seems as a contradiction to the strong analgesic effect of opioids and the higher amount of analgesics received by those patients. We think that the right interpretation of this observation needs to consider two facts: first, patients were asked for their maximum pain levels, when the effect of opioids of the recovery room (normally piritramide) had ended. Second, none of the patients, including those requiring opioids in the recovery room, received opioids in the ward. Most patients received metamizole $(91.8 \%)$, or ibuprofen (5.9\%) (see Table 2). This is an indication that the need of opioids in the recovery room should lead to application of opioids in the ward to prevent significant increase of maximum pain.

Indeed non-opioids are considered as standard medication with oral and fast application after surgery to reduce postoperative pain to a minimum. This is in accordance with the current literature and current guidelines [25].

But despite these facts, 28 patients (32.9\%) presented severe pain with NRS values exceeding levels of $\geq 4$ which indicates inadequate pain management. These patients maybe would have profited from an additional medication with opioids. Given this interpretation, we have to acknowledge that also on our ward nearly a third of our patients were undersupplied with adequate pain medication, especially opioids, which is a worldwide phenomenon $[\underline{4}, \underline{5}, \underline{6}]$. Therefore, each pain management concept should comprise escalating steps in case of inadequately controlled pain, e.g., by the additional dispensation of opioids on an as-needed basis and/or use of patient-controlled analgesia (PCA) devices. Furthermore, the preoperative use of NSAIDs could be considered as it is recommended before third molar surgery and after other types of operation affecting bones and joints. The QUIPS project might be helpful to identify these deficits and correct it by sensitizing staff to use opioids more frequently and earlier, especially in patients requiring opioids in the recovery room.

To our opinion, QUIPS has been shown to be an effective and practical instrument to measure postoperative pain after specific surgical procedures like midfacial fracture repair. Further improvement of acute postoperative pain management requires continued monitoring of the outcome of the analgesic treatment.

\section{Conclusion}

In an investigation of the outcome of postoperative acute pain management after midfacial repair using QUIPS, overall observed pain intensities were moderate. Analysis of process and outcome parameters revealed that inadequate pain management was prevalent especially in patients exhibiting duration of surgery above the median and patients requiring opioids in the recovery room. The application of QUIPS has shown adequate results to rate the outcome of acute postoperative pain management. 
Notes

\section{Conflict of interest statement}

The authors declare that they have no conflict of interest. There were no sources of funding or financial relationships.

\section{References}

1. Kehlet $\mathrm{H}$ (2004) Effect of postoperative pain treatment on outcome-current status and future strategies. Langenbecks Arch Surg 389:244-9. doi: 10.1007/s00423-004-0460-4

2. Kehlet H, Wilkinson RC, Fischer HB, Camu F (2007) PROSPECT: evidence-based, procedure-specific postoperative pain management. Best Pract Res Clin Anaesthesiol 21:149-59

3. Gartner R, Jensen MB, Nielsen J, Ewertz M, Kroman N, Kehlet $H$ (2009) Prevalence of and factors associated with persistent pain following breast cancer surgery. JAMA 302:1985-92. doi: 10.1001/jama.2009.1568

4. Rathmell JP, Wu CL, Sinatra RS, Ballantyne JC, Ginsberg B, Gordon DB, Liu SS, Perkins FM, Reuben SS, Rosenquist RW, Viscusi ER (2006) Acute post-surgical pain management: a critical appraisal of current practice, December 2-4, 2005. Reg Anesth Pain Med 31:1-42. doi: 10.1016/i.rapm.2006.05.002

5. Apfelbaum JL, Chen C, Mehta SS, Gan TJ (2003) Postoperative pain experience: results from a national survey suggest postoperative pain continues to be undermanaged. Anesth Analg 97:534-40, table of contents

6. Benhamou D, Berti M, Brodner G, De Andres J, Draisci G, Moreno-Azcoita M, Neugebauer EA, Schwenk W, Torres LM, Viel E (2008) Postoperative analgesic therapy observational survey (PATHOS): a practice pattern study in 7 central/southern European countries. Pain 136:134-41. doi: 10.1016/j.pain.2007.06.028

7. Fries BE, Simon SE, Morris JN, Flodstrom C, Bookstein FL (2001) Pain in U.S. nursing homes: validating a pain scale for the minimum data set. Gerontologist 41:173-9

8. Gureje O, Simon GE, Von Korff M (2001) A cross-national study of the course of persistent pain in primary care. Pain 92:195-200

9. Warfield CA, Kahn CH (1995) Acute pain management. Programs in U.S. hospitals and experiences and attitudes among U.S. adults. Anesthesiology 83:1090-4

10. Fletcher D, Fermanian C, Mardaye A, Aegerter P (2008) A patient-based national survey on postoperative pain management in France reveals significant achievements and persistent challenges. Pain 137:441-51. doi: 10.1016/j.pain.2008.02.026

11. Mularski RA, White-Chu F, Overbay D, Miller L, Asch SM, Ganzini L (2006) Measuring pain as the 5th vital sign does not improve quality of pain management. J Gen Intern Med 21:607-12. doi: 10.1111/j.15251497.2006.00415.x

12. Gordon DB, Dahl JL (2004) Quality improvement challenges in pain management. Pain 107:1-4

13. Ellis E, Zide MF, Carmichael J (2006) Surgical approaches to the facial skeleton. Lippincott Williams \& Wilkins, Philadelphia

14. Myles PS, Williams DL, Hendrata M, Anderson H, Weeks AM (2000) Patient satisfaction after anaesthesia and surgery: results of a prospective survey of 10,811 patients. Br J Anaesth 84:6-1015.

15. Sommer M, Geurts JW, Stessel B, Kessels AG, Peters ML, Patijn J, van Kleef M, Kremer B, Marcus MA (2009) Prevalence and predictors of postoperative pain after ear, nose, and throat surgery. Arch Otolaryngol Head Neck Surg 135:124-30. doi: 10.1001/archoto.2009.3

16. Ballantyne JC, Carr DB, deFerranti S, Suarez T, Lau J, Chalmers TC, Angelillo IF, Mosteller F (1998) The comparative effects of postoperative analgesic therapies on pulmonary outcome: cumulative meta-analyses of randomized, controlled trials. Anesth Analg 86:598-612

17. Beattie WS, Buckley DN, Forrest JB (1993) Epidural morphine reduces the risk of postoperative myocardial ischaemia in patients with cardiac risk factors. Can J Anaesth 40:532-41. doi: 10.1007/BF03009738

18. Gordon DB, Dahl JL, Miaskowski C, McCarberg B, Todd KH, Paice JA, Lipman AG, Bookbinder M, Sanders SH, Turk DC, Carr DB (2005) American pain society recommendations for improving the quality of acute and 
cancer pain management: American pain society quality of care task force. Arch Intern Med 165:1574-80. doi: $10.1001 /$ archinte.165.14.1574

19. Rawal N, Berggren L (1994) Organization of acute pain services: a low-cost model. Pain 57:117-23

20. Rosenquist RW, Rosenberg J (2003) Postoperative pain guidelines. Reg Anesth Pain Med 28:279-88

21. Meissner W, Mescha S, Rothaug J, Zwacka S, Goettermann A, Ulrich K, Schleppers A (2008) Quality improvement in postoperative pain management: results from the QUIPS project. Dtsch Arztebl Int 105:865-70. doi: 10.3238/arztebl.2008.0865

22. Hyllested M, Jones S, Pedersen JL, Kehlet H (2002) Comparative effect of paracetamol, NSAIDs or their combination in postoperative pain management: a qualitative review. $\mathrm{Br} J$ Anaesth 88:199-214

23. Rothaug J, Weiss T, Meissner W (2013) How simple can it get? Measuring pain with NRS items or binary items. Clin J Pain 29(3):224-32

24. Meissner W, Ullrich K, Zwacka S (2006) Benchmarking as a tool of continuous quality improvement in postoperative pain management. Eur J Anaesthesiol 23:142-8. doi: 10.1017/S026502150500205X

25. Savoia G, Alampi D, Amantea B, Ambrosio F, Arcioni R, Berti M, Bettelli G, Bertini L, Bosco M, Casati A, Castelletti I, Carassiti M, Coluzzi F, Costantini A, Danelli G, Evangelista M, Finco G, Gatti A, Gravino E, Launo C, Loreto M, Mediati R, Mokini Z, Mondello E, Palermo S, Paoletti F, Paolicchi A, Petrini F, Piacevoli Q, Rizza A, Sabato AF, Santangelo E, Troglio E, Mattia C (2010) Postoperative pain treatment SIAARTI Recommendations 2010. Short version. Minerva Anestesiol 76:657-67 